\title{
Effect Analysis of Simotang Oral Liquid on Functional Dyspepsia of Incoordination between the Liver and the Spleen and Gastrointestinal Hormone
}

\author{
Muhua Liang ${ }^{1, a}$, Xiangqian $\mathrm{Xu}{ }^{1, b}$ \\ ${ }^{1}$ Henan Province Hospital of Traditional Chinese Medicine, Zhengzhou, China \\ ${ }^{\mathrm{a}}$ email, ${ }^{\mathrm{b}}$ email
}

Keywords: Simotang oral liquid; functional dyspepsia; incoordination between the liver and the spleen; gastrointestinal hormone

Abstract. This paper investigates the effect of Simotang oral liquid on functional dyspepsia of incoordination between the liver and the spleen and gastrointestinal hormone. The research objects were the 100 patients with functional dyspepsia treated in our hospital from January 2014 to October 2015. They were randomly divided into observation group $(n=50$ cases $)$ and control group $(n=50$ cases) according to even number-odd method. The control group were treated with domperidone tablets in the treatment, and the observation group were treated with Simotang oral liquid. After 2 weeks of treatment, compare the motilin, gastric emptying situation and symptoms as well as plasma substance $\mathrm{P}$ of two groups of patients. The overall response rate of functional dyspepsia of incoordination between the liver and the spleen for observation group was $80 \%$ while the control group was $72 \%$. Compare the two groups, we can see the difference was not statistically significant, $\mathrm{p}>0.05$. After treatment, the nausea, epigastric fullness and abdominal pain and other symptoms of patients were significantly lower than that before treatment, and the difference was significant, which was statistically significant, $\mathrm{p}>0.05$. The observation group was significantly better than the control group, and the difference was significant, which was statistically significant, $\mathrm{p}>0.05$. The total effective rate of gastric emptying in patients in the observation group was $76 \%$, and that in the control group was $68 \%$, respectively. The difference was not statistically significant, $\mathrm{p}>0.05$. That patients with functional dyspepsia of incoordination between the liver and the spleen use Simotang oral treatment is safe and effective, which can effectively promote gastrointestinal emptying and regulate motilin and substance $P$.

\section{Introduction}

Functional dyspepsia is a common clinical and multiple digestive disease, mainly showing postprandial bloating and abdominal discomfort and other symptoms. Simotang oral liquid has been widely used in the treatment of functional dyspepsia, which has a better therapeutic effect for indigestion and stagnation symptoms. In this study, the author applied Simotang oral liquid to functional dyspepsia and achieved satisfactory results, which are reported below.

\section{Object and method}

\section{Research object}

The research objects were the 100 patients with functional dyspepsia treated in our hospital from January 2014 to October 2015, and all objects of this study are in line with the diagnostic criteria for functional dyspepsia in the relevant literatures. Patients are aged 18 to 65 years, haven't participated in clinical research and taken over western medicine associated with the disease before 14 days entering the group; unconsolidated liver, kidney, heart and blood system in patients with severe primary disease. All objects were informed of the study and signed informed consent. Patients included 52 males and 48females; the minimum age of 28 years old and the maximum age of 64 years old, median age ( $41.4 \pm 8.1)$ years old; the average duration $(2.6 \pm 1.2)$ years. They were randomly divided into observation group and control group according to even number-odd method. The 
baseline data for all objects, such as sex, age, duration, etc., was not statistically significant through statistical analysis, $\mathrm{p}>0.05$.

\section{Treatment method}

The patients in control group were treated with domperidone tablets (Zhunzi H20052322 \& O Pharmaceutical Co., Ltd. Nanjing), each taking a dose of 10mg, 3 times a day; analog Simotang oral liquid (Zhunzi Z20025044 Hunan Hansen pharmaceutical Co., Ltd.), each taking a dose of 20mL, 3 times a day. The patients in observation group were treated with Simotang oral liquid (Zhunzi Z20025044 Hunan Hansen Pharmaceutical Co., Ltd.), each taking a dose of 20mL, three times a day; analog domperidone tablets (Zhunzi H20052322 pharmaceutical Co., Ltd. Nanjing), each taking a dose of 10mg, three times a day. Observation drugs and analog drugs have basically the same appearance, a course of 14 days. The patients are forbidden to either drink coffee or tea during treatment, or eating chocolate and high fat foods.

\section{Outcome measures}

(1) Symptom observation: It is scored according to the standard of relevant literatures. By the severity of symptoms, it can grade with 0 , Level 1 , Level 2, Level 3, and the main symptoms are epigastric fullness and nausea with 0 point, 2 points, 4 points, 6 points, secondary symptom with 0 point, 1 point, 2 points and 3 points. The symptoms and signs of two groups of patients were scored according to the above criteria before and after treatment. (2) According to RIA, plasma motilin and substance P content are detected in strict accordance with the instructions for testing operations. (3) Record occurrence time of adverse events duration and severity of the stress and the measures taken and the return transfer in detail. (4) Take routine examination, urine, science, liver and kidney function, heart EEG for one time each before and after treatment.

\section{Efficacy determination}

Evaluation of gastric emptying is: marked: gastric emptying rate increases greater than or equal to $30 \%$; effective: gastric emptying rate increases greater than $20 \%$ and less than $30 \%$; invalid: gastric emptying rate increases less than $20 \%$, or there is no change in the emptying amount.

\section{Statistical method}

Collect experimental data and use statistical software for data processing in data package SPSS20.0, count data and measurement data were represented with $(\mathrm{n} \%)$ and $(\mathrm{x} \pm \mathrm{s})$, respectively. The differences between the groups were tested by $\mathrm{x}^{2}$ and $\mathrm{t}$. When $\mathrm{P}<0.05$, the difference was statistically significant.

\section{Results}

\section{Clinical efficacy comparison of two groups of patients after treatment}

The overall response rate of functional dyspepsia of incoordination between the liver and the spleen for observation group was $80 \%$ while the control group was $72 \%$. Compare the two groups, we can see the difference was not statistically significant, $\mathrm{p}>0.05$, see table 1 .

Table 1 Clinical efficacy comparison of two groups of patients after treatment [n(\%)]

\begin{tabular}{ccccccc}
\hline Group & Cases & Cured(n) & Marked(n) & Effective(n) & Invalid(n) & $\begin{array}{c}\text { Total efficiency } \\
\text { rate (\%) }\end{array}$ \\
\hline $\begin{array}{c}\text { Observation } \\
\text { group }\end{array}$ & 50 & $9(18.00)$ & $19(38.00)$ & $12(24.00)$ & $10(20.00)$ & 80.00 \\
$\begin{array}{c}\text { Control } \\
\text { group }\end{array}$ & 50 & $8(16.00)$ & $16(32.00)$ & $12(24.00)$ & $14(28.00)$ & 72.00 \\
X2 & & 0.1417 & 0.7912 & 0.0000 & 1.7544 & 1.7544 \\
p & & 0.7066 & 0.3737 & 1.0000 & 0.1853 & 0.1853 \\
\hline
\end{tabular}




\section{Syndrome treatment comparison of two groups of patients after treatment}

After treatment, the nausea, epigastric fullness and abdominal pain and other symptoms of patients were significantly lower than that before treatment, and the difference was significant, which was statistically significant, $\mathrm{p}>0.05$. The observation group was significantly better than the control group, and the difference was significant, which was statistically significant, $\mathrm{p}>0.05$.

\section{Gastric emptying comparison of two groups of patients after treatment}

Gastric emptying in patients in the observation group: marked(20), effective(18), invalid(12), the total effective rate was $76 \%$. Gastric emptying in patients in the control group: marked(16), effective(18), invalid(16), the total effective rate was $68 \%$. The difference was not statistically significant, $\mathrm{p}>0.05$.

\section{Motilin and plasma substance $P$ comparison of two groups of patients before and after treatment}

Before and after treatment, the difference between motilin and plasma substance P was marked, which was statistically significant, $\mathrm{p}>0.05$. The difference between groups was not statistically significant, $\mathrm{p}>0.05$, see table 2 .

Table 2 Motilin and plasma substance P comparison of two groups of patients before and after treatment ( $\mathrm{x} \pm \mathrm{s}$, $\mathrm{pg} / \mathrm{mL})$

\begin{tabular}{cccccc}
\hline Group & Cases & \multicolumn{2}{c}{ Plasma substance P } & \multicolumn{2}{c}{ Motilin } \\
\cline { 3 - 6 } & & Before & After & Before & After \\
\hline $\begin{array}{c}\text { Observation } \\
\text { group }\end{array}$ & 50 & $36.4 \pm 6.2$ & $42.3 \pm 5.2 \#$ & $203.2 \pm 7.6$ & $231.9 \pm 7.2 \#$ \\
Control group & 50 & $35.9 \pm 5.4$ & $41.9 \pm 5.6 \#$ & $201.7 \pm 8.2$ & $229.2 \pm 6.8 \#$ \\
t & & 0.4300 & 0.3701 & 0.9487 & 1.9278 \\
P & & 0.6681 & 0.7121 & 0.3451 & 0.0568 \\
\hline
\end{tabular}

Note, comparison with that before treatment $\# \mathrm{p}>0.05$

\section{Discussion}

Functional dyspepsia is a common clinical and multiple digestive disease, mainly showing postprandial bloating and abdominal discomfort and other symptoms. Traditional Chinese Medicines think that gastrointestinal is attributable to the function of Chinese medicine spleen and stomach, which are the main place for human body to digest food. Eating into the stomach, under the action of maturity and receiving in the stomach and transport of spleen, it will effectively converse to subtle effects that body requires, but the function of spleen and stomach depends on the operation and coordination and stomach movements, and has a direct relationship with liver failure sparse vent and air-strip of. Usually, the case of liver failure catharsis, thus resulting in the spleen losing health movement, with the abnormal performance of cashier operation. Therefore, dredging air and eliminating swelling is the most basic method of treatment, with the ultimate goal to restore normal brain-gut axis.

Motilin is mainly a special gastrointestinal hormone jejunum cells secrete, which can effectively stimulate the digestive tract on mechanical movements and physiological electrical activity, and thus induce strong contractions of the stomach and the more prominent sports of small intestine section, thereby there is a very important regulatory role in gastrointestinal movement, especially the complex migrating during digestion.

Simotang oral liquid is consisted by the betel nut, Citrus aurantium, woody and Lindera, where woody has the effect of eliminating pain, carrying along the air, and adjust temperature in the stomach, named as King medicine; betel nut has the effect of dredging air and removing the power, Citrus aurantium has the effect of carrying along the air and eliminating bloating, named as minister medicine; Lindera has the effect of regulating liver and rationalizing air, named as adjuvant. Several drugs used together can have good effect. 
In summary, patients with functional dyspepsia of incoordination between the liver and the spleen use Simotang oral liquid for treatment, which is safe and effective, and can effectively promote gastrointestinal emptying and effectively regulate motilin and substance P.

\section{References}

[1] Zhou S, Cai G, Wan S, et al. The clinical efficacy of Simotang oral liquid on functional dyspepsia (liver temper Stagnation) and the impact on serum NO, AchE, CCK, SP. Journal of Emergency in Traditional Chinese Medicine, 2014, 23 (10): 1791-1792, 1833.

[2] Wen H. Simotang oral liquid jointing with digestion and diarrhea treatment of children with functional dyspepsia 126 cases. China Pharmaceuticals, 2013,22 (18): 95-96.

[3] Meng F. Summary of Simotang oral liquid for its treatment of children with digestive dysfunction 60 cases. Hunan Journal of Traditional Chinese Medicine, 2014, 30(10): 65-66.

[4] Chen J, Liang D. The clinical efficacy observation of Simotang oral liquid for its treatment of functional dyspepsia. World Latest Medicine Information, 2016, 16(94):133-133, 139.

[5] Zhang L. Clinical investigation of the treatment of functional dyspepsia by Mosapride and Deanxit associated with Simotang oral liquid. 